Canadian

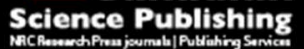

Canadian Journal of Civil Engineering Revue canadienne de génie civil

\title{
Influence of Signal Countdown Timer on Efficiency and Safety at Signalized Intersections
}

\begin{tabular}{|r|l|}
\hline Journal: & Canadian Journal of Civil Engineering \\
\hline Manuscript ID & cjce-2016-0267.R1 \\
\hline Manuscript Type: & Article \\
\hline Complete List of Authors: & $\begin{array}{l}\text { Biswas, Sabyasachi; Indian Institute of Technology Roorkee, Department } \\
\text { of Civil Engineering } \\
\text { Ghosh, Indrajit ; Indian Institute of Technology Roorkee, Department of } \\
\text { Civil Engineering } \\
\text { Chandra, Satish; CSIR-Central Road Research Institute (CRRI) }\end{array}$ \\
\hline Keyword: & $\begin{array}{l}\text { Countdown Timer, Dilemma Zone, Red Light Violation, Saturation Flow, } \\
\text { Start-Up Lost Time }\end{array}$ \\
\hline &
\end{tabular}

SCHOLARONE ${ }^{\text {m }}$

Manuscripts 


\title{
Influence of Signal Countdown Timer on Efficiency and Safety at Signalized Intersections
}

\author{
Sabyasachi Biswas* \\ Research Scholar, \\ Department of Civil Engineering, \\ Indian Institute of Technology (IIT) Roorkee, \\ India- 247667. \\ Tel: +918791475379
}

Email: sabyasachibiswas01@gmail.com sabyadec@iitr.ac.in

*Corresponding Author

\author{
Indrajit Ghosh \\ Assistant Professor, \\ Department of Civil Engineering, \\ Indian Institute of Technology (IIT) Roorkee, \\ India- 247667. \\ E-mail: indrafce@,iitr.ac.in
}

\section{Satish Chandra}

Director, CSIR-Central Road Research Institute (CRRI),

Delhi - Mathura Road, India 110025.

Email: satisfce@gmail.com 


\begin{abstract}
Signal countdown timers (SCTs) are expected to help drivers with better decision-making processes. Because of the inconsistent outcomes from previous studies associated with them, the present study evaluates the influence of SCTs on intersection efficiency and safety by conducting "before and after" study at three signalized intersections located in New Delhi. A methodology is proposed to estimate the start-up lost time at signalized intersections under highly heterogeneous condition. Green signal countdown timer found to have no influence on saturation flow, though its red component helped reduce the start-up lost time significantly. These two components also affect the red light violations at the intersection locations - by increasing violations during the last $10 \mathrm{~s}$ red and decreasing them during the initial $10 \mathrm{~s}$ of red. Timer-off scenario enlarged total ranges of both Type I and II dilemma zones at the onset of yellow and brought Type II dilemma zone earlier.
\end{abstract}

Keywords: Countdown Timer, Dilemma Zone, Red Light Violation, Saturation Flow, StartUp Lost Time 


\section{Introduction}

In India, due to the presence of both slow and fast-moving vehicles in the traffic stream, long cycle lengths are common at medium to large size intersections located in urban areas. Even after having long cycle lengths, cycle failures are frequent during peak hour at many major intersections in metropolitan cities resulting in long waiting time. It has been observed that majority of motorists standing in the queue at the intersection approach under red light do not switch off their engines, which result in wastage of precious fossil fuel. To reduce fuel consumption while waiting at the red light, Petroleum Conservation Research Association (PCRA installed signal countdown timers (SCTs) in major Indian cities. These timers have two components. The component that provides information to the drivers about the remaining time left in the red phase is known as red signal countdown timer (RSCT). Whereas, the other component, which shows the remaining time during the green phase of the signal cycle, is commonly termed as green signal countdown timer (GSCT). Long waiting at traffic signal often gives rise to drivers' frustration and stress, as well as their inattention to signal changes. These circumstances, ultimately, tend to contribute to longer time for motorists to start their vehicles and proceed through intersections (commonly known as start-up lost time or SULT) as well as various traffic violations whereby drivers disregard the traffic signals, leading to the occurrence of red light violations (RLVs).

By displaying the remaining phase time to drivers, countdown-timers are expected to reduce fuel consumption, the anxiety of drivers standing in the queue, crashes and improve the capacity of the intersections (Long et al., 2011). Interestingly, their expected effect came with mixed realization to different researchers from developing countries, especially in asia. Kidwai et al. (2005) conducted a study in Malaysia by considering three intersections having no countdown timers and four intersections with countdown timers. They observed that countdown timers have no impact on the saturation flow, thus having no significant effect on intersection capacity. However, these timers reduced RLVs by 50 percent. Lum and Halim 
(2006) in Singapore observed that the number of drivers who decided to stop during the amber time had increased 6.2 times after GSCT installation and the RLVs reduced by 65 percent within 1.5 months since its installation. However, GSCT lost its initial effectiveness after 7.5 months under high traffic flows as RLVs bounced back to almost the same amount as it was before the signal's installation. On the other hand, the increase in red stopping due to the presence of GSCT was sustainable over the longer term, though a relatively small reduction was noted. In Taiwan, Ministry of Transportation conducted a before-and-after study (Chen et al., 2007) within one year of RSCT and GSCT installation at 187 signalized intersections. It was observed that the number of reported accidents and injuries at intersections having GSCT increased by 100 and 33 percent, respectively. While the number of accidents and injuries were found to decrease by 50 percent for intersections with RSCT. Similarly, drivers tend to accelerate aggressively when GSCT was present, but they are more likely to obey red signal in the presence of RSCT.

Fajita et al. (2007) conducted a study at two intersection locations in Turkey. The presence of RSCT was found to reduce SULT. In another study based in Malaysia, Ibrahim et al. (2008) found that presence of countdown timers has little effect on car travel time to reach the stop line (initial delay) from different positions within the queue, but they reduce the discharge headway of cars in the queue significantly, which results in higher saturation flows. While 30 percent of the observed cycles had occurrences of RLVs in the presence of timers, non-timer scenario accounted for 24 percent. In Thailand, Limanond et al. (2009) studied an intersection for two days - once when the timer was operating and another when it was switched off. While SULT was observed to reduce in the presence of timer, their effect on saturation headway was trivial. Sharma et al. (2009) also noted that the presence of timers could reduce SULT and increase the discharge rate during the last half of the green. Chiou and Chang (2010) studied the effect of GSCT and RSCT at four different time periods in Taiwan- before its installation, and 1.5 months, 3 months and 4.5 months after its installations. Early start 
ratios of the leading vehicles waiting in different waiting areas were found to reduce initially but returned to the same level before RSCT installation for both peak and non-peak hours indicating poorer safety condition over the long run. At the end of 4.5 months after the installation, RSCT was found to be associated with reduced SULT, discharge headway during peak hours as well as the cumulative start-up delay. It was also observed that RSCT reduced the red-running ratio and number of vehicles ejecting to cross the intersection, but it extended the dilemma zone by approximately $28 \mathrm{~m}$. Consequently, drivers found it difficult to decide between stopping and proceeding through the intersection. Limanond et al. (2010) studied an intersection during the non-peak hours and observed that while the presence of timer led to the reduction in SULT for through movement, it also reduced saturation flow, thus jeopardizing the effectiveness of timers. GSCT reduced the number of RLVs at starting of red phase by 50 percent. In China, Ma et al. (2010) concluded that GSCT helped to eliminate dilemma zone (DZ) and reduced RLVs. Long et al. (2011) carried out a study in China at four urban intersections and concluded that timers' presence encouraged the drivers for entering the intersection late, which in turn could lead to hazardous RLVs. Harshitha et al. (2012) has conducted a study at an intersection in Chennai and concluded that under the heterogeneous condition $_{2}$ no-timer case followed conventional headway distribution though it had increased headway values towards the end of the queue. On the other hand, the presence of timer case observed steady discharge headway similar to the stabilized minimum discharge headway of the no-timer case. Thus, these timers considerably reduced the SULT and delays, resulting in a more efficient intersection. Liu et al. (2012) in China observed that countdown timers significantly affected the SULT of both through and protected left turn movements, but it has little effect on saturation headways. The reduction in saturation headways due to timers' presence was statistically significant for through movements, but not for left-turn movements. The timers resulted in headway compressions at the end of each queue. Raksuntorn (2012) studied thirty-two signalized intersections in Thailand and observed that countdown timers do 
not have any effect on the saturation headway, but total SULT was reduced by 33 percent resulting in an increase in the capacity of signalized intersection. Sharma et al. (2012) carried out another study in Chennai and found that the presence of timers reduced SULT and number of RLVs for cars and two-wheelers at the starting of red, but it increased the number of RLVs of all three type of vehicles (cars, motorized two-wheelers, and motorized autorickshaws) at the end of red. It was also observed that the presence of timers resulted in the reduction of the percentage of RLV cycles and mean RLVs per RLV cycle at the starting of red. Long et al. (2013) observed that the presence of timers assisted drivers to make a better decision and helped to reduce dangerous driving maneuvers during the transition period. Rijavec et al. (2013) in Slovenia found that red and/or amber running violation rate is higher when the countdown display is turned off. Zhang et al. (2013) studied two intersections in China and observed that RSCTs reduced the first headway of discharged vehicles and fluctuations of vehicular headways while they were in the queue. The capacity of the through movement was increased by 5 to 10 percent after the installations of the GSCT, but it did not influence the order of the vehicle attaining saturation headway.

Based on previous findings, it is evident that there are studies where SCTs were found to be associated with reduced SULT, DZ, and RLVs. There are some other research works, which contradicted these findings. The key reason behind these conflicting findings could be the difference in traffic conditions and driver behaviors among the countries, even from one city to another. The studies, which were carried out in developing countries (namely, China, Bangkok, Malaysia, India, and Taiwan) found that the presence of GSCT and RSCT affected traffic characteristics and driving behaviors in different ways and consequently influenced the efficiency and safety potential at signalized intersections. Therefore, precautions should be taken while installing these SCTs at urban intersections. Interestingly, no engineering study is conducted in India to evaluate their effect on intersection efficiency and safety prior to installations of these timers. Sharma et al. (2009, 2012), Harshitha et al. (2012) and Devalla 
et al. (2015) have concentrated primarily on evaluating the effect of timers on approach speed, queue discharge characteristics and RLVs only. All of these parameters are very much driver-specific and may change from one place to another. The present study was taken up with the objective of investigating the effect of countdown timers on various traffic characteristics and driver behaviors by considering several measures of effectiveness (MOEs). This study also develops a prediction model, which can accurately estimate SULT at signalized intersection under highly heterogeneous condition.

\section{Data Collection}

To analyze the influence of different components of signal countdown timers (GSCT and RSCT) on intersection efficiency and safety, three signalized intersections (designated as IS1, IS2, and IS3 respectively) were chosen from New Delhi, India. All of them have similar geometric characteristics. Two intersections had a cycle length of $180 \mathrm{~s}$ while the third had the cycle length of $165 \mathrm{~s}$. All the intersections have left channelized (for the left-hand drive), and are free from the influence of any nearby bus stops, roadside parking, and away from CBD areas, schools, colleges, etc. All the locations are equipped with SCTs. The snapshot of a typical site is shown in Fig 1.

\section{Fig 1}

For conducting "before and after" study to evaluate the effectiveness of SCTs, it was decided to consider the same intersection both in the presence and absence of digital timers. Initially, data were collected using the videography technique on one approach of each of the selected intersections when SCTs were on (represented as IST1, IST2, and IST3 for first, second and third intersections respectively). To collect data at the same intersection locations in the absence of SCT (denoted as ISW1, ISW2, and ISW3 respectively), assistance was sought from Delhi Traffic Police to switch off the SCTs.

\section{Table 1}


As reported in Table 1, both "before" and "after" period observations were made on weekdays during the same time period (between 10:00 am and 4:15 pm) to replicate the traffic conditions during timer-on and timer-off situations. Two cameras were used for the data collection purpose. One camera was mounted on a vantage point adjacent to the intersection to cover at least $100 \mathrm{~m}$ upstream from the intersection stop line. This camera recorded the traffic approaching the intersection along the selected approach. The second camera recorded the signal indication displayed to the traffic for the same approach. Traffic movements were recorded both in the presence and absence of countdown timers at three selected approaches and thus six different sets of video data were obtained from the whole data collection process. The key characteristics of study locations along with the details of data collection during the study period are given in Table 1.

\section{Table 2}

All vehicles were classified into 5 different categories. The projected area of each classified vehicle were actually measured in the field (Biswas and Ghosh 2017). Types of the vehicles included under each category and their average dimensions are given in Table 2. Vehicle composition at each study location, both in the presence and absence of SCTs, are also presented in Table 2. It can be observed that the total car (small and big car combined) proportion is about 70 percent at Intersection 1 (IS1) and Intersection 3 (IS3), whereas it is around 50 percent at Intersection 2 (IS2). The highest percentage of motorized two-wheelers and auto-rickshaws (motorized three wheelers) were observed at IS2. Buses constituted a very low proportion of the traffic stream during the data collection.

\section{Analysis and Results}

To analyze the influence of signal countdown timers, several measures of effectiveness (MOEs) related to intersection efficiency and safety were identified. While saturation flow and start-up lost time (SULT) were examined for studying the effect of these SCTs on 
intersection efficiency, red light violations (RLVs) and dilemma zone (DZ) were considered for safety related evaluation.

\section{Effect on Traffic Efficiency}

All the required information were extracted from the video data by playing videos on a large screen. For the estimation of the saturation flow, Passenger Car Unit (PCU) values for different vehicles at study intersections were determined both in the presence and absence of SCTs.

\section{Estimation of Passenger Car Unit (PCU)}

Passenger car unit (PCU) is a measure to convert all types of vehicles in a traffic stream into an equivalent number of passenger cars. It helps to bring down a non-uniform traffic stream with different kinds of vehicles to a uniform traffic stream consisting of passenger cars only. Researchers across the world have used several methods to find PCU value of a particular vehicle category taking into account different factors. In this study, headway method (Brown and Ogden, 1988, Cuddon \& Odgen, 1992, and Saha et al., 2009) has been used to estimate PCU values for different categories of vehicles. For the present study, headway was measured from back of the leading vehicle to back of the following vehicle. The average headways maintained by different vehicle categories, e.g., car to car, big car to big car, auto to auto, motorized two-wheeler to motorized two-wheeler and bus to bus were extracted from the recorded videos. The PCU factors of different vehicle types were determined using Eq. $[1]$.

$$
\mathrm{PCU}_{\mathrm{i}-\mathrm{i}}=\frac{h_{i-i}}{h_{c-c}}
$$

Where, PCU $\mathrm{i}_{\mathrm{i}-\mathrm{i}}$ represents PCU of $i$-category vehicle; $\mathrm{h}_{\mathrm{i}-\mathrm{i}}$ represents average headway of $i$ category vehicle followed by another type $i$-category vehicle, and $h_{c-c}$ represents average headway of a car followed by another car.

Table 3 
Tables 3 shows the descriptive statistics of the headway values and the PCU values for different vehicle categories on each intersection approach in the presence and absence of signal countdown timers. For one approach, no bus to bus combination was observed and therefore PCU values for the bus could not be estimated.

\section{Effect on Saturation Flow}

Saturation flow is a macro-level indicator of the performance of an intersection. It indicates the probable capacity of an intersection if operating under ideal conditions. During the initial green phase, first few vehicles in the queue take some extra time to react and proceed through the intersection. The rate of vehicles passing through the stop line increases as vehicles accelerate. Headway between the successive vehicles decreases until they start following each other at a relatively steady headway through the rest of the queue. This steady headway is commonly known as saturation headway. The saturation flow rate of an intersection approach is simply the reciprocal of the saturation headway. Saturation flow for each study approach was estimated by using the conventional method (Hadiuzzaman et al. 2008, Biswas and Ghosh 2017), as given by Eq. [2]. First of all, the classified vehicles count was made for all the vehicles clearing the intersection approach during saturation green time and these numbers were multiplied by their respective PCU values to get the saturation flow in PCU for each cycle. Values of saturation flow for each observed cycle have been calculated using Eq. $[2]$.

$$
\text { Saturation Flow, } S F=\left[\sum n_{i} P C U_{i-i}\right] \frac{3600}{g_{S}}
$$

\section{Table 4}

The highest value among all values has been presented as saturation flow for that approach in the presence/absence of GSCT, are given in Table 4. Additionally, the average and standard deviation of all saturation flow values along with other related statistics for different study approaches are presented in Table 4. Based on the t-statistics and p-values, it can be 
concluded that at all the study approaches, saturation flow values were not significantly different under the circumstances when the timer was off or on (shown in Table 4). Therefore, it is implied that SCTs have no significant effect on the saturation flow as reported by several earlier studies (Ibrahim et al., 2008; Kidwai et al., 2005; Raksuntorn, 2012). However, this observation contradicts the findings of Limanond et al. (2010), who observed that saturation flow reduced in the presence of timer and Zhang et al. (2013) who found that saturation flow increased when the timer was on.

\section{Effect on Start-Up Lost Time (SULT)}

SULT refers to the lost time at the beginning of a green phase. When the signal turns green after the red phase, the actual headways of first few vehicles were observed to be longer than the saturation headway due to the perception-reaction time and time taken for acceleration. As per US HCM (Highway Capacity Manual, 2010), SULT is estimated by adding the time difference between saturation headway and headways of the first four vehicles in the queue. However, in India, estimation of SULT by the traditional method does not work due to highly heterogeneous traffic condition and the non-lane based movement of vehicles. Motorized two-wheelers, because of their small size and better maneuverability, can percolate through small gaps and reach the front of the queue to move immediately once the signal turns green. It makes the initial discharge also quite significant. At the same time, saturation headway varies among different vehicle categories under this non-lane discipline traffic condition. It has been observed that motorized two-wheelers and three-wheelers (auto-rickshaws) maintain comparatively shorter headway and utilize any possible free space available between other vehicles due to their smaller size and easier maneuverability.

Keeping these in mind, a method is proposed in the present study to estimate SULT under heterogeneous traffic condition. Fig 2 shows the variation of traffic flow for each $5 \mathrm{~s}$ interval of green and amber phase. The start-up lost time can be determined as follows: 
Mean saturation flow rate (s) is the average of discharge rates in time interval $2(5-10 \mathrm{~s})$ to 9 (40-45 s) as shown in Fig 2. SULT is due to the lower discharge rate in the first interval (0-5 s) and therefore, the area of the first rectangle adgh should be equal to the area of the rectangle $b e f h$, where $b h$ is the effective green in the first interval, $b e$ is the mean saturation flow rate and $a b$ is the start-up lost time. Similarly, end lost time $(\mathrm{km})$ can be computed by putting area lmnp equal to area $l k j i$. The total lost time will be $(a b+\mathrm{km})$.

Fig 2

Considering, area $a d g h=$ area $b e f h$

$$
\text { Or, } a d \times a h=b e \times b h
$$

where, $a d=\mathrm{q}_{0}$, initial traffic flow in the first time interval $\mathrm{t}(5 \mathrm{~s}$ in Fig 2)

$$
\begin{aligned}
& a h=\text { time interval } \mathrm{t}(5 \mathrm{~s}) \\
& b e=\text { mean saturation flow rate }(\mathrm{s}), \mathrm{PCU} / \mathrm{t} \mathrm{s} \text { interval of a particular cycle } \\
& \mathrm{bh}=\text { effective green in the first interval }=\frac{q_{0} \times t}{\mathrm{~s}}
\end{aligned}
$$

Therefore, if ab (which is equal to SULT) is represented as $l_{s}$

$$
l_{s}=\mathrm{t}-\frac{q_{0} \times t}{s}
$$

Mean saturation flow (s) was calculated by taking the average of traffic flow for all $5 \mathrm{~s}$ interval, where flow is more than $5 \mathrm{PCU} / 5 \mathrm{~s}$ in the stabilized zone. Vehicles which started moving from their positions during the red light (considered as RLVs at the end of a red phase in the present study) were not considered in the calculation of SULT. In this proposed method, SULT for every individual cycle has been calculated by using the Eq. [4]. The estimated SULT values for the studied approaches, both in the presence and absence of red signal countdown timer (RSCT), are presented in Table 5.

\section{Table 5}


For all approaches, the value of SULT was significantly higher when RSCTs were switched off. At the first intersection (IS1), SULT increased from 1.64 to 3.16 when the RSCT was switched off. Similarly, SULT increased significantly at other two intersections in the absence of RSCT display (1.25 s to $2.78 \mathrm{~s}$ at IS2 and $1.02 \mathrm{~s}$ to $2.79 \mathrm{~s}$ at IS3). This trend is consistent with the findings observed in previous studies (Limanond et al., 2009, 2010; Raksuntorn, 2012; Sharma et al., 2012). The reason is that when drivers were waiting in the queue during red, the timer information (the number of seconds remaining for the signal to become green) helped them to prepare early. This led to reduction in the perception-reaction time of drivers to accelerate, which ultimately resulted into a lower SULT in the presence of RSCT. Also, it is interesting to note that higher variance existed in SULT values when the RSCT was on; it is due to the wide range of SULT values observed. In the presence of RSCT, smaller vehicles, e.g., two-wheelers and autos, started their engines early and were ready for rolling once the signal turned green. As a result of this early starting of vehicles, SULT values in the presence of RSCT was observed to have higher variance.

\section{Effect on Traffic Safety}

The data extracted from the video were used to evaluate the effect of SCTs on vehicular violation and dilemma zone at signalized intersections. Few numbers of vehicles, which violated red light, were counted both in the presence and absence of countdown timer (both RSCT and GSCT). The present study also estimates the range of dilemma zones along study approaches which come into play during the amber phase.

\section{Effect on Red Light Violations (RLVs)}

Red light violation (RLV) refers to the situation when a vehicle travels past the solid stop line after the light has turned red. For the present study, violations that occurred during initial and final $10 \mathrm{~s}$ of red phase, have been considered as RLVs. More number of RLVs represents reduced safety potential at intersection locations (Mohamedshah et al., 2000 and FHWA, 
2004). RLVs during initial red phase typically refer to the red light runners who travel through the intersection during red phase just after amber phase. On the other hand, RLVs at the end of red phase indicate the instances when vehicles, waiting in the queue during red phase, crossed the stop line or waited at the edge of the road for the green phase to start by occupying the zebra crossing location. The safety implications of these two violations are entirely different in nature. While RLVs at the starting of red can often induce severe injury/fatal angle crashes, the latter ones interrupt pedestrian movements along zebra crossing during the vehicular red phase; thus exposing the pedestrians to higher risk.

To assess the effect of SCTs on the RLVs, all the RLVs along the study approaches were noted down both in the presence and absence of SCTs (both GSCT and RSCT) and were compared. Since geographic conditions and phase timings remained the same for with and without timer cases, any changes in RLVs can be attributed to the impact of timer information. Fig 3 (a) shows a plot of the percentage of cycles where RLV occurred. It can be observed that at IS1 8.7 percent of the cycles had RLVs in the presence of timer, which jumped to 29.63 percent in the absence of timer. Similarly, for the IS2, the percentage of cycles where RLV occurred increased from 16.67 percent in the case of timer-on scenario to 27.59 percent when timer display was off. This result contradicts the findings obtained by Sharma et al. (2012). Countdown timer did not have an impact on total RLVs at IS3. To have a better understanding, the percentage of cycles where RLVs took place was estimated separately for the initial and final $10 \mathrm{~s}$ of red. It was observed that the number of cycles where RLVs occurred during the initial $10 \mathrm{~s}$ of red phase increased in the absence of GSCT (4.35 to 25.93 percent at IS1, 8.33 to 20.69 percent at IS2 and 25 to 50 percent at IS3). This is probably due to the fact that drivers could adjust their speeds when approaching the intersection with the aid of countdown timer. Therefore, they had enough time to decide either to clear the intersection or stop in anticipation of red phase, thus reducing the RLVs. In contrast, when countdown timers were off, drivers had no prior information about the amber 
and red phase which often resulted in the last second attempt to pass. On the other hand, RLVs during the last $10 \mathrm{~s}$ of red phase decreased when the RSCT was off (8.7 to 7.41 percent, 12.5 to 10.35 percent and 31.25 to 6.25 percent at IS1, IS2 and IS3 respectively). This shows that many drivers used RSCT information to make early start decisions, which might have increased the percentage of cycles with RLVs during the last $10 \mathrm{~s}$ of red phase. Similar results were obtained by Sharma et al. (2012) at an intersection in Chennai, India.

Fig 3

Another MOE which was considered for evaluating the effect of SCT is Mean RLV per RLV cycle which represents the number of RLVs averaged over all the cycles having at least one RLV in that cycle (Sharma et al. 2012). In the present study, mean RLV per RLV cycle has been estimated for both initial and final $10 \mathrm{~s}$ of red. Additionally, overall mean RLV per RLV cycle for all the study approaches has also been calculated. Values of all of these RLV related parameters have been presented in Fig 3(b). The overall mean RLV per RLV cycle increased from 1 to 1.375 at IS1 in the absence of SCT. Although, there is no reduction in mean RLV per RLV cycle during the first and last $10 \mathrm{~s}$ of red. On the other hand, it was observed that overall mean RLV per RLV cycle increased from 2 to 2.5 and from 2.56 to 4.66 at IS2 and IS3 respectively in the absence of timer. It is evident from Fig 3(b) that mean RLV per RLV cycle at these two intersections (IS2 and IS3) increased during the initial $10 \mathrm{~s}$ of red and declined over the last $10 \mathrm{~s}$ of red phase when the timer was off. It can also be observed that total percentage of RLV cycles (summation of the percentage of RLV cycles during initial and final $10 \mathrm{~s}$ of red phase) reduced in the presence of SCTs for all the study sites. Similarly, if the total number of mean RLV per RLV cycles for both initial and final stage of red is taken into consideration, it was found to be decreasing when SCT (GSCT and RSCT respectively) was on.

Fig 4 
From Fig 4(a) and (b), it was observed that most of the RLVs had been contributed by the motorized two wheelers at all study approaches during the last $10 \mathrm{~s}$ of red, whereas they had more involvement in RLV at IS1 and IS2 during the initial $10 \mathrm{~s}$ of red. It is interesting to note that small cars had the highest contributions towards RLVs at IS3 during first $10 \mathrm{~s}$, though there is no involvement of small cars during the last $10 \mathrm{~s}$ of red. Overall, the study observed that there were fewer occurrences of RLVs during initial $10 \mathrm{~s}$ and more RLVs during final $10 \mathrm{~s}$ of red phase due to the influence of GSCT and RSCT respectively.

\section{Effect on Dilemma Zone}

To assess the effect of SCT, more specifically its GSCT component, on the dilemma zone (DZ), the definition of both Type I and II DZs was utilized. Initially, Gazis et al. (1960) developed the model of DZ, which is commonly termed as the GHM model. In this model, the difference between the maximum crossing distance $\left(\mathrm{X}_{\mathrm{C}}\right)$ and the minimum stopping distance $\left(\mathrm{X}_{\mathrm{S}}\right)$ is defined as Type I DZ, when $\mathrm{X}_{\mathrm{C}}$ is less than $\mathrm{X}_{\mathrm{S}} \cdot \mathrm{X}_{\mathrm{C}}$ and $\mathrm{X}_{\mathrm{S}}$ can be computed by using Eq.s [5] and [6], respectively

$$
\begin{aligned}
& X_{S}=V_{0} \tau+\frac{V_{0}^{2}}{2 a_{1}} \\
& X_{C}=V_{0} Y+\frac{1}{2} a_{2}(Y-\tau)^{2}-L-W
\end{aligned}
$$

DZ can also be determined based upon the probability of drivers' decision to stop the vehicles at stop line during the amber phase. Parsonson et al. (1974) defined DZ as an area that starts where 90 percent of vehicles will stop and ends where only 10 percent of vehicles will stop when they see a yellow indication. This DZ is generally known as Type II DZ. Historically Type I DZ has been represented in terms of length (meter), while Type II DZ has been estimated in terms of time (s). Retting and Greene (1997) showed that DZ acts as a key influencing factor on the occurrence of RLVs. Longer DZs result into more confusion among drivers, leading to crash potentials at signalized intersection locations (Parsonson, 1978; Sheffi and Mahmassani 1981, Elmitiny et al. 2010). The present study attempts to evaluate 
the effect of timers on DZs by estimating the two DZs along the selected approaches for both timers on and off situations. No past studies were carried out to examine the effect of signal countdown timers on Type II DZ (commonly termed as indecision zone).

In the present study, only small cars were considered for the analysis of DZs as they were observed in maximum numbers during the amber phase. Initially, the speeds $\left(\mathrm{V}_{0}\right)$ with which small cars crossed the stop line during the amber time were determined for all study approaches. From Table 6, it is clear that at first intersection when the GSCT was on (IST1), small cars crossed the stop line at a higher speed during the amber time as compared to the condition without timer (ISW1) (i.e, $15.55 \mathrm{vs} 16.63 \mathrm{~m} / \mathrm{s}$ ). Similarly at the second intersection, small cars exhibited higher speeds during timer-on (IST2) situation in comparison with timeroff (ISW2) situation (13.54 vs $15.64 \mathrm{~m} / \mathrm{s}$ ). Both the differences in speed were found to be statistically significant at a 95-percent confidence level. This shows that the presence of GSCT encouraged drivers of small car to cross the stop line at higher speeds. The maximum deceleration rate $\left(a_{1}\right)$, which is defined as the 85 th percentile value of all observed instantaneous deceleration rates during the amber phase, was estimated from the distance versus time relationship. Similarly, the maximum acceleration rate $\left(a_{2}\right)$, the 85 th percentile value of all the instantaneous acceleration rates during the amber phase, was also calculated. For drivers' perception-reaction time $(\tau)$, related data were extracted from collected videos. As all the study locations are in New Delhi, an average value of $\tau=1.14 \mathrm{~s}$ was used for the subsequent analyses. Finally, ranges of Type I DZs were estimated for sites using Eq. [5] and $[6]$.

\section{Table 6}

For determining the Type II DZ, observed frequencies and the cumulative stopping probability of vehicles against the time to stop line (TTS) were plotted as shown in Fig 5(a) 
and 5(b) respectively. The ranges of Type II DZ were then determined by considering the TTS values corresponding to 10 and 90 percent cumulative stopping probabilities.

Fig 5

Table 6 summarizes the estimated values of DZs (Type I and II) at different study approaches. From Table 6, it is evident that deviation in behavioral parameters directly affected the Types I and II DZ for selected approaches. Type I DZs for the study approaches were less $(7.86 \mathrm{~m}$ for IST1 and $9.70 \mathrm{~m}$ for IST2) for GSCT-on conditions as compared to ones obtained by the same approaches in the absence of timer (12.69 $\mathrm{m}$ for ISW1 and $11.15 \mathrm{~m}$ for ISW2) which is consistent with the results obtained by Ma et al. (2010), but in contrast to the findings reported by Chio and Chang (2010). With the timer-on condition, Type II DZ was located between 4.0 to $5.76 \mathrm{~s}$ and 4.13 to $4.58 \mathrm{~s}$ at the onset of amber phase for IST1 and IST2 respectively. Whereas, it was located between 2.86 to $5.34 \mathrm{~s}$ and 2.17 to $3.18 \mathrm{~s}$ at the onset of amber phase for ISW1 and ISW2 respectively. It was found that GSCT-off situations brought Type II DZ earlier by 1.14 and $1.96 \mathrm{~s}$ for first and second intersection respectively and enlarged its total range by $0.72 \mathrm{~s}$ for IS1 and $0.56 \mathrm{~s}$ for IS 2 as compared to that of the GSCTon condition. The values of Type II DZs estimated were found to be almost equal or smaller than the ones observed by other researchers, e.g., 2.5-5 s (Zegeer, 1977), 2.0-4.5 s (Chang et al., 1985), 3.0-5.0/6.0 s (Bonneson et al., 1994), and 1.7-2.7 s (Papaioannou, 2007).

\section{Conclusions}

In India, signal countdown timers are being installed at several major intersection locations without any engineering studies related to their impacts on intersection safety and efficiency. This is the first kind of study which looked at the issue of signal countdown timers (more specifically its component, GSCT, and RSCT) in multiple ways. This paper empirically investigates the impacts of the SCTs on traffic efficiency and violations at three signalized intersections in New Delhi, both in the presence and absence of digital timers. Both traffic 
and signal indication data along with the timer information were collected using video cameras. It was observed that these timers had no significant effect on saturation flow. Because of the distinctive characteristic associated with highly heterogeneous and non-lane based driving condition prevalent in India, a simple method is taken up to estimate the startup lost time in the study. When RSCT was on, drivers' SULT reduced significantly at all the selected locations due to the tendency of early starting of vehicles (utilizing the time-related information provided by RSCT) while standing in the queue during the red phase. Therefore, it is evident that the presence of RSCT was associated with reduced SULT. To evaluate the impact of SCTs on traffic safety, vehicular violations during initial and final red phases were looked at by considering the percentage of RLV cycles and mean RLV per RLV cycle. The presence of RSCT led to higher RLVs during the last $10 \mathrm{~s}$ of red. The digital timers enabled the drivers, standing in the queue during red phase, to see the time remaining for the green phase to come. A number of drivers moved ahead of stop line during the final stage of red phase resulting in more occurrences of RLVs. However, the opposite effect was observed in the presence of GSCT. Lower RLVs were observed during the initial $10 \mathrm{~s}$ of red phase when GSCT display was on and vice-versa. The drivers could not change their speed while approaching the intersection with timer-off condition resulting in a very late entry into the intersections (RLVs at the starting of red phase). Total number of RLVs, i.e., RLVs occurring at the starting and end of the red phase, is found to be decreasing in the presence of SCTs. The effect of GSCTs on the dilemma zone was also investigated by considering the movements of small cars at the onset of yellow phase. No prior studies have observed SCT's effect on Type II DZ. Therefore, in the present study GSCT's effect on both Type-I and TypeII DZs were examined. It was observed that ranges of both Type I and Type II DZs for small cars reduced in the presence of GSCT. At the same time, when compared with GSCT-on situations, GSCT-off conditions brought Type II DZ earlier.

Overall, it was observed that the presence of timer displays during red phase (i.e., RSCT) 
helped in reducing start-up lost time though it increased the vehicular violations during final $10 \mathrm{~s}$ red phase. Whereas timer-related information provided by digital timer during green phase (i.e., GSCT) led to a reduction of RLVs during initial $10 \mathrm{~s}$ of red phase. However, GSCT did not affect the saturation flow. Interestingly, GSCT-off situations were found to be associated with a longer length for dilemma zones and bringing them earlier along the studied intersection approaches.

In summary, it is perceived that signal countdown timers influenced traffic efficiency and safety potential at signalized intersections in a mixed way. GSCT has significant positive effect on road traffic safety in terms of reduced dilemma zone along intersection approaches and red light violations during the initial red phase. However, GSCT has no significant impact on intersection efficiency in terms of saturation flow. On the other hand, the presence of RSCT was responsible for reduced SULT calculated from proposed methodology, but it resulted into higher propensity of RLVs during final $10 \mathrm{~s}$ of red phase. In a combined way, the presence of countdown timers does not have much influence on the intersection efficiency, but the information provided by them can affect traffic safety at the signalized intersection locations. Based on these findings, it is suggested to switch off RSCT at the intersection locations enabled with signal countdown timers. It will help reduce the number of RLVs at the end of the red phase, which will further bring down the total number of vehicular violations during the red phase. Under such circumstances (RSCT-off scenario), the real effectiveness of these newly-installed SCTs will be perceived in terms of improved traffic safety at signalized intersections. This study can be further extended by including data from other signal countdown timer-enabled intersections located in different parts of India.

\section{Acknowledgment}

The work reported in this paper is the part of an on-going research project on "Effect of Countdown Display on Traffic Flow Characteristics and Driver Behaviour at Signalised 
Intersections", sponsored by DST-SERB, New Delhi, India. The financial assistance provided by the sponsoring agency for traffic studies is gratefully acknowledged.

\section{References}

Biswas, S., and Ghosh, I. 2017. Estimation of Passenger Car Units and Stream Equivalency Factor at Signalized Intersections Under Heterogeneous Traffic Condition. Transportation Research Board 96th Annual Meeting, No. 17- 06803.

Bonneson, J. A., McCoy, P. T., and MoenBrian, A. 1994. Traffic Detector Design and Evaluation Guidelines. TRP-02-31-93, Nebraska Department of Road Lincoln, NE.

Brown, G. and Ogden K. W. 1988. The Effect of Vehicle Category on Traffic Signal Design: A Re-Examination of Through Car Equivalents. 14th ARRB Conference, 2, 27-37.

Chang, M. S., Messer, C. J., and Santiago, A. J. 1985. Timing Traffic Signal Change Intervals Based on Driver Behavior. Transportation Research Record: Transportation Research Board, Transportation Research Board of the National Academies, Washington, D.C.Washington, DC, 1027, Transportation Research Board of the National Academies, Washington, D.C, 20-30.

Chen I. C., Chang, K. K., Chang, C. C., and Lai, C. H. 2007. The Impact Evaluation of Vehicular Signal Countdown Displays. Research Report. Taiwan.

Chiou, Y.C., and Chang, C.H. 2010. Driver Responses to Green and Red Vehicular Signal Countdown Displays: Safety and Efficiency Aspects. Accident; analysis and prevention, 42(4), 1057-65.

Cuddon, A. P., K. W. Ogden, and P. Fellow. 1992. The Effect of Heavy Vehicles on Saturation Flows at Signalized Intersections. 16th ARRB Conference, 5, 1-18.

Devalla, J., Biswas, S., and Ghosh, I. 2015. The Effect of Countdown Timer on the Approach Speed at Signalised Intersections. Procedia Computer Science, 52, 920-925.

Elmitiny, N., Yan, X., Radwan, E., Russo, C., Nashar, D., 2010. Classification analysis of 
driver's stop/go decision and red-light running violation. Accident Analysis \& Prevention, 42 (1), 101-111.

FHWA 2004. Signalized Intersections: Informational Guide, Publication No. FHWA-HRT04-091, Federal Highway Administration, USA.

Fujita, M., Suzuki, K., and Yilmaz, C. 2007. Behavior and Consciousness Analyzes on Effect of Traffic Signals Including Countdown Device. Journal of the Eastern Asia Society for Transportation Studies, 6, 2289-2304.

Gazis, D., Herman, R., and Maradudin, A. 1960. The Problem of the Amber Signal Light in Traffic Flow. Operations Research, 8(1), 112-132.

Harshitha, M. S., Agarwal, S., and Vanajakshi, L. 2012. Headway Analysis at Signalised Intersections with and without Countdown Timer. Highway Research Journal, January, 3340.

Hadiuzzaman, M., M. Rahman, and M. A. Karim. Saturation Flow Model at Signalized Intersection for Non-lane Based Traffic. Canadian Journal of Transportation, 2 (1), 2008.

HCM 2010. Highway Capacity Manual, Fifth Edition.Transportation Research Board of the National Academies, Washington, D.C..

Ibrahim, M. R., Karim, M. R., and Kidwai, F. a. 2008. The Effect of Digital Countdown Display on Signalized Junction Performance. American Journal of Applied Sciences, 5(5), $479-482$.

Kidwai, F. A., Ibrahim, M. R., and Karim, M. R. 2005. Traffic Flow Analysis of Digital Count Down Signalized Urban Intersection. Journal of Mathematics and Technology, 5, $1301-1308$.

Koonce, P., Rodergerdts, L., and Lee, K. 2008. Signal Timing Manual. FHWA-HOP-08-023 Federal Highway Administration. 
Limanond, T., Chookerd, S., and Roubtonglang, N. 2009. Effects of Countdown Timers on Queue Discharge Characteristics of Through Movement at a Signalized Intersection. Transportation Research Part C: Emerging Technologies, 17(6), 662-671.

Limanond, T., Prabjabok, P., and Tippayawong, K. 2010. Exploring Impacts of Countdown Timers on Traffic Operations and Driver Behavior at a Signalized Intersection in Bangkok. Transport Policy, 17(6), 420-427.

Liu, P., Yu, H., Ma, J., and Wang, S. 2012. Evaluating the Effects of Signal Countdown Timers on Queue Discharge Characteristics at Signalized Intersections in China. Transportation Research Record: Journal of the Transportation Research Board, (2286, Transportation Research Board of the National Academies, Washington, D.C., 39-48.

Long, K., Han, L. D., and Yang, Q. 2011. Effects of Countdown Timers on Driver Behavior After the Yellow Onset at Chinese Intersections. Traffic Injury Prevention, 12(5), 538-44.

Long, K., Liu, Y., and Han, L. D. 2013. Impact of Countdown Timer on Driving Maneuvers After the Yellow Onset at Signalized Intersections: An Empirical Study in Changsha, China. Safety Science, 54, 8-16.

Lum, K. M., and Halim, H. 2006. A Before and After Study on Green Signal Countdown Device Installation. Transportation Research Part F: Traffic Psychology and Behaviour, 9(1), 29-41.

Ma, W., Liu, Y., and Yang, X. 2010. Investigating the Impacts of Green Signal Countdown Devices: Empirical Approach and Case Study in China. Journal of Transportation Engineering, 136(11), 1049-1055.

Mohamedshah, Y. M., Chen, L. W. and Council F. M. 2000. Association of Selected Intersection Factors with Red-Light-Running Crashes: HSIS Summary Report: FHWA-RD$00-112$

Papaioannou, P. 2007. Driver behavior, dilemma zone and safety effects at urban signalized intersections in Greece. Accident; analysis and prevention, 39(1), 147-58. 
Parsonson, P. S., Roseveare, R. W., and Thomas, J. M. (1974). Small Aare Detection at Intersection Approaches. Journal of Transportation Engineering, 44(5), 8-17.

Parsonson, P.S. 1978. Signalization of high speed. Isolated intersection, Transportation Research Record, 681, 34-42

Raksuntorn, W. 2012. The Effects of Countdown Signals on Intersection Capacity. International Transaction Journal of Engineering, Management, \& Applied Sciences \& Technologies., 3(2), 159-165.

Retting, R. A., and Greene, M. A. 1997. Influence of traffic signal timing on red light running and potential vehicle conflicts at urban intersections. Transportation Research Record: Journal of the Transportation Research Board, (1595), Transportation Research Board of the National Academies, Washington, D. C. 1-7.

Rijavec, R., Zakovšek, J., and Maher, T. 2013. Acceptability Of Countdown Signals at an Urban Signalized Intersection and Their Influence on Drivers Behaviour. Promet - Traffic \& Transportation, 25(1), 63-71.

Saha, P., H. M. I. Mahmud, Q. S. Hossain, and M. Z. Islam. Passenger Car Equivalent (PCE) of Through Vehicles At Signalized Intersections in Dhaka Metropolitan City, Bangladesh. IATSS Research, 33(2), 2009, 99-104.

Sheffi, Y. and Mahmassani.,H. 1981. A model of driver behavior at high speed signalized intersections, Transportation Science, 15, 50-61

Sharma, A., Vanajakshi, L., Girish, V., and Harshitha, M. S. 2012. Impact of Signal Timing Information on Safety and Efficiency of Signalized Intersections. Journal of Transportation Engineering, Washington, D.C, 138(4), 467-478.

Sharma, A., Vanajakshi, L., and Rao, N. 2009. Effect of Phase Countdown Timers on Queue Discharge Characteristics Under Heterogeneous Traffic Conditions. Transportation Research Record: Journal of the Transportation Research Board, (2130), Transportation Research Board of the National Academies, Washington, D.C., 93-100. 
Zegeer, C. V. 1977. Effectiveness of Green Extension Systems at High-Speed Intersections. Lexington, KY.

Zhang, D. L., Wei, D. H., Li, D. Z., Zhang, D. Y., Wenbo, S., Zhaocheng, H., Xi, X., and Feifei, X. 2013. Exploring Impacts of Countdown Timers on Queue Discharge Characteristics of Through Movement at Signalized Intersections. Procedia - Social and Behavioral Sciences, Elsevier B.V., 96, 255-264. 


\section{List of Symbols}

GSCT - Green signal countdown timer;

RSCT - Red signal countdown timer;

RLV - Red light violation;

$\overline{\mathrm{h}}_{\mathrm{c}-\mathrm{c}} \quad$ - Average headway of a car followed by a car, s;

$\overline{\mathrm{h}}_{\mathrm{x}-\mathrm{x}} \quad$ - $\quad$ Average headway of a type $\mathrm{x}$ vehicle followed by a type $\mathrm{x}$ vehicle, s.;

$\overline{\mathrm{h}}_{\mathrm{c}-\mathrm{x}} \quad$ - $\quad$ Average headway of a car followed by a type $\mathrm{x}$ vehicle, s.;

$\overline{\mathrm{h}}_{\mathrm{x}-\mathrm{c}} \quad$ - $\quad$ Average headway of a type $\mathrm{x}$ vehicle followed by a car, s.;

$\mathrm{PCU}_{\mathrm{i}-\mathrm{i}} \quad$ - $\quad$ PCU of vehicle category $\mathrm{i}$;

$\mathrm{h}_{\mathrm{i}-\mathrm{i}} \quad-\quad$ Average headway for $\mathrm{i}^{\text {th }}$ vehicle category, s.;

$\mathrm{h}_{\mathrm{c}-\mathrm{c}} \quad$ - $\quad$ Average headway for cars, sec;

SF - Saturation flow, PCU per hour of green;

$\mathrm{n}_{\mathrm{i}} \quad$ - $\quad$ Number of the vehicle category $\mathrm{i}$

$\mathrm{g}_{\mathrm{s}} \quad$ - $\quad$ Saturated green period, $\mathrm{s}$

$\mathrm{V}_{0} \quad$ - A vehicle's approach speed (m/s)

$\tau \quad-\quad$ Driver's perception-reaction time (s)

$\mathrm{a}_{1} \& \mathrm{a}_{2}$ - Maximum deceleration and acceleration rate $\left(\mathrm{m} / \mathrm{s}^{2}\right)$

$\mathrm{Y} \quad-\quad$ Duration of yellow interval (s)

L $\quad-\quad$ Vehicle length $(\mathrm{m})$

$\mathrm{W} \quad$ - Intersection width (m) 
Table 1. Characteristics of intersections and vehicular composition during data collection

\begin{tabular}{|c|c|c|c|c|c|c|}
\hline $\begin{array}{l}\text { Key } \\
\text { Characteristics }\end{array}$ & \multicolumn{2}{|c|}{ Intersection 1 (IS1) } & \multicolumn{2}{|c|}{ Intersection 2 (IS2) } & \multicolumn{2}{|c|}{ Intersection 3 (IS3) } \\
\hline Location & \multicolumn{2}{|c|}{$\begin{array}{l}\text { Maxmuller Marg and } \\
\text { Lodhi Road }\end{array}$} & \multicolumn{2}{|c|}{$\begin{array}{l}\text { Lodhi Road and Bhisma } \\
\text { Pitamah Marg }\end{array}$} & \multicolumn{2}{|c|}{$\begin{array}{c}\text { Bhishma Pitamah Marg } \\
\text { and Kendriya Vidyalaya } \\
\text { Lodhi Road }\end{array}$} \\
\hline Target Approaches & \multicolumn{2}{|c|}{ East Bound } & \multicolumn{2}{|c|}{ North Bound } & \multicolumn{2}{|c|}{ West Bound } \\
\hline Target Movements & \multicolumn{2}{|c|}{$\begin{array}{l}\text { Through and Right } \\
\text { Turning }\end{array}$} & \multicolumn{2}{|c|}{$\begin{array}{l}\text { Through and Right } \\
\text { Turning }\end{array}$} & \multicolumn{2}{|c|}{$\begin{array}{l}\text { Through and Right } \\
\text { Turning }\end{array}$} \\
\hline Number of Lanes & \multicolumn{2}{|c|}{3} & \multicolumn{2}{|c|}{3} & \multicolumn{2}{|c|}{3} \\
\hline Approach Width & \multicolumn{2}{|c|}{$9.6 \mathrm{~m}$} & \multicolumn{2}{|c|}{$9.0 \mathrm{~m}$} & \multicolumn{2}{|c|}{$9.6 \mathrm{~m}$} \\
\hline Cycle Length & \multicolumn{2}{|c|}{$180 \mathrm{~s}$} & \multicolumn{2}{|c|}{$180 \mathrm{~s}$} & \multicolumn{2}{|c|}{$165 \mathrm{~s}$} \\
\hline Green Time & \multicolumn{2}{|c|}{$45 \mathrm{~s}$} & \multicolumn{2}{|c|}{$35 \mathrm{~s}$} & \multicolumn{2}{|c|}{$45 \mathrm{~s}$} \\
\hline Amber Time & \multicolumn{2}{|c|}{$5 \mathrm{~s}$} & \multicolumn{2}{|c|}{$5 \mathrm{~s}$} & \multicolumn{2}{|c|}{$5 \mathrm{~s}$} \\
\hline $\begin{array}{l}\text { Data Collection } \\
\text { Time }\end{array}$ & \multicolumn{2}{|c|}{$10: 00$ am to $12: 00 \mathrm{pm}$} & \multicolumn{2}{|c|}{$3: 00 \mathrm{pm}$ to $4: 00 \mathrm{pm}$} & \multicolumn{2}{|c|}{$3: 00 \mathrm{pm}$ to $4: 15 \mathrm{pm}$} \\
\hline Timer Condition & On (IST1) & Off (ISW1) & On (IST2) & Off (ISW2) & On (IST3) & Off (ISW3) \\
\hline $\begin{array}{l}\text { No. of Cycles } \\
\text { Observed }\end{array}$ & 40 & 40 & 20 & 20 & 21 & 21 \\
\hline $\begin{array}{l}\text { Data Collection } \\
\text { Date }\end{array}$ & $23 / 12 / 14$ & $24 / 12 / 14$ & $20 / 01 / 15$ & $21 / 01 / 15$ & $11 / 2 / 15$ & $12 / 2 / 15$ \\
\hline
\end{tabular}


Table 2. Vehicular Composition during data collection at the study locations

\begin{tabular}{|c|c|c|c|c|c|c|c|c|c|}
\hline $\begin{array}{c}\text { Vehicle } \\
\text { Type }\end{array}$ & $\begin{array}{l}\text { Vehicles } \\
\text { included }\end{array}$ & $\begin{array}{c}\text { Vehicle } \\
\text { Length } \\
\text { (m) }\end{array}$ & $\begin{array}{c}\text { Vehicle } \\
\text { Width } \\
\text { (m) }\end{array}$ & IST1 & ISW1 & IST2 & ISW2 & IST3 & ISW3 \\
\hline Small Car & Car & 3.72 & 1.44 & $61 \%$ & $60 \%$ & $41 \%$ & $42 \%$ & $59 \%$ & $62 \%$ \\
\hline \multirow[t]{2}{*}{ Big Car } & SUV, Van & 4.58 & 1.77 & $9 \%$ & $12 \%$ & $6 \%$ & $9 \%$ & $11 \%$ & $10 \%$ \\
\hline & 3-Wheeler & & & & & & & & \\
\hline Auto & $\begin{array}{c}\text { Auto } \\
\text { Rickshaw }\end{array}$ & 3.2 & 1.4 & $15 \%$ & $15 \%$ & $20 \%$ & $23 \%$ & $10 \%$ & $11 \%$ \\
\hline 2-Wheeler & $\begin{array}{c}\text { Scooter, } \\
\text { motorcycles }\end{array}$ & 1.87 & 0.64 & $13 \%$ & $11 \%$ & $31 \%$ & $23 \%$ & $18 \%$ & $15 \%$ \\
\hline Bus & Standard bus & 10.1 & 2.43 & $1 \%$ & $1 \%$ & $1 \%$ & $2 \%$ & $1 \%$ & $1 \%$ \\
\hline
\end{tabular}


Table 3. Estimated PCU values for different vehicle categories

\begin{tabular}{|c|c|c|c|c|c|c|}
\hline $\begin{array}{c}\text { Intersection } \\
\text { Condition }\end{array}$ & Vehicle type & $\begin{array}{l}\text { Average } \\
\text { headway }\end{array}$ & Std. dev. & $\begin{array}{c}\text { Average } \\
\text { Saturation Flow } \\
\text { rate (vphg) }\end{array}$ & Sample Size & PCU \\
\hline & Car & 2.1 & 1.9 & 1714.29 & 747 & 1 \\
\hline & Big Car & 2.81 & 0.028 & 1281.14 & 12 & 1.34 \\
\hline \multirow[t]{5}{*}{ IST1 } & Auto & 1.94 & 1.52 & 1855.67 & 60 & 0.92 \\
\hline & Tw & 1.04 & 0.81 & 3461.54 & 54 & 0.49 \\
\hline & Bus & 3.38 & 1.515 & 1065.09 & 6 & 1.6 \\
\hline & Car & 2.07 & 1.06 & 1739.13 & 657 & 1 \\
\hline & Big Car & 2.13 & 0.87 & 1690.14 & 48 & 1.02 \\
\hline \multirow[t]{5}{*}{ ISW1 } & Auto & 1.97 & 1.51 & 1827.41 & 125 & 0.95 \\
\hline & Tw & 1.21 & 0.91 & 2975.21 & 91 & 0.58 \\
\hline & Bus & 3.38 & 0.02 & 1065.09 & 3 & 1.63 \\
\hline & Car & 2.4 & 1.11 & 1500 & 118 & 1 \\
\hline & Big Car & 2.31 & 1 & 1558.44 & 14 & 0.96 \\
\hline \multirow[t]{5}{*}{ IST2 } & Auto & 2.42 & 1.7 & 1487.6 & 18 & 1.01 \\
\hline & TW & 1.03 & 0.34 & 3495.15 & 37 & 0.43 \\
\hline & Bus & - & - & - & Nil & - \\
\hline & Car & 2.52 & 1.21 & 1428.57 & 124 & 1 \\
\hline & Big Car & 2.63 & 1.45 & 1368.82 & 20 & 1.04 \\
\hline \multirow[t]{5}{*}{ ISW2 } & Auto & 2.24 & 2.32 & 1607.14 & 42 & 0.89 \\
\hline & TW & 1.03 & 0.66 & 3495.15 & 20 & 0.41 \\
\hline & Bus & - & - & - & Nil & - \\
\hline & Car & 1.94 & 0.73 & 1855.67 & 308 & 1 \\
\hline & Big Car & 2.09 & 0.97 & 1722.49 & 46 & 1.07 \\
\hline \multirow[t]{5}{*}{ IST3 } & Auto & 1.5 & 0.63 & 2400 & 78 & 0.77 \\
\hline & TW & 1.01 & 0.95 & 3564.36 & 34 & 0.52 \\
\hline & Bus & 4.29 & 1.01 & 839.16 & 12 & 2.2 \\
\hline & Car & 2.02 & 0.97 & 1782.18 & 358 & 1 \\
\hline & Big Car & 2.3 & 1.15 & 1565.22 & 38 & 1.14 \\
\hline \multirow[t]{3}{*}{ ISW3 } & Auto & 1.71 & 0.93 & 2105.26 & 92 & 0.85 \\
\hline & TW & 0.99 & 0.64 & 3636.36 & 42 & 0.49 \\
\hline & Bus & 4.38 & 1.37 & 821.92 & 17 & 2.17 \\
\hline
\end{tabular}


Table 4. Descriptive statistics of saturation flow at different study approaches

\begin{tabular}{|c|c|c|c|c|c|c|c|}
\hline $\begin{array}{c}\text { Intersection } \\
\text { Condition }\end{array}$ & $\begin{array}{c}\text { Saturation } \\
\text { Flow } \\
\text { (PCU/hr) }\end{array}$ & $\begin{array}{c}\text { Mean } \\
\text { Saturation } \\
\text { Flow/ } \\
\text { Std. dev. } \\
\text { (PCU/hr) }\end{array}$ & df & $\mathbf{t}_{\text {stat }}$ & $\begin{array}{c}\mathbf{t}_{\text {critical (two- }} \\
\text { tail) }\end{array}$ & p-value & $\begin{array}{l}\text { Remarks } \\
\text { regarding } \\
\text { difference }\end{array}$ \\
\hline $\begin{array}{c}\text { IST1 } \\
\text { ISW1 }\end{array}$ & $\begin{array}{l}6316 \\
6142\end{array}$ & $\begin{array}{l}5337 / 498 \\
4927 / 520\end{array}$ & 66 & 1.23 & 1.99 & 0.014 & $\begin{array}{c}\text { Not } \\
\text { Significant }\end{array}$ \\
\hline $\begin{array}{l}\text { IST2 } \\
\text { ISW2 }\end{array}$ & $\begin{array}{l}6653 \\
6237\end{array}$ & $\begin{array}{l}5781 / 537 \\
5538 / 520\end{array}$ & 34 & 1.39 & 2.03 & 0.17 & $\begin{array}{c}\text { Not } \\
\text { Significant }\end{array}$ \\
\hline ISW3 & 6483 & $\begin{array}{l}6253 / 345 \\
5958 / 307\end{array}$ & 33 & 1.79 & 2.02 & 0.008 & $\begin{array}{c}\text { Not } \\
\text { Significant }\end{array}$ \\
\hline
\end{tabular}


Table 5. Start-up loss time (SULT) calculation at different approaches

\begin{tabular}{ccccccccc}
\hline Sl. No & Approach & $\begin{array}{c}\text { Start-up } \\
\text { loss time } \\
\text { (sec) }\end{array}$ & Variance & df & $\mathbf{t}_{\text {stat }}$ & $\mathbf{t}_{\text {critical }}$ & p-value & $\begin{array}{c}\text { Remarks } \\
\text { regarding } \\
\text { difference }\end{array}$ \\
\hline 1 & IST1 & 1.64 & 1.74 & 46 & 3.64 & 2.01 & 0.0006 & Significant \\
2 & ISW1 & 3.16 & 1.09 & & & & & \\
3 & IST2 & 1.25 & 1.89 & & & & & \\
4 & ISW2 & 2.78 & 1.65 & & 3.03 & 2.03 & 0.0047 & Significant \\
5 & IST3 & 1.02 & 0.63 & & & & & \\
6 & ISW3 & 2.79 & 0.43 & 33 & 7.41 & 2.03 & $1.60 \mathrm{E}-08$ & Significant \\
\hline
\end{tabular}


Table 6. Estimation of dilemma zone at the study approaches

\begin{tabular}{|c|c|c|c|c|c|c|c|c|c|c|}
\hline $\begin{array}{l}\text { Intersection } \\
\text { Condition }\end{array}$ & $\begin{array}{c}\text { Mean } \\
\text { Speed/std } \\
\operatorname{dev}(\mathrm{m} / \mathrm{s})\end{array}$ & $\begin{array}{l}85^{\text {th }} \text { Acc. } \\
/ \text { std dev } \\
\text { a2 }\left(\mathrm{m} / \mathrm{s}^{2}\right)\end{array}$ & $\begin{array}{l}85^{\text {th Dec. }} \\
/ \text { std dev } \\
\text { a1 }\left(\mathrm{m} / \mathrm{s}^{2}\right)\end{array}$ & $\tau(\mathbf{s})$ & W (m) & $L(m)$ & $Y(s)$ & $\begin{array}{c}\text { Xs / Xc } \\
\text { (m) }\end{array}$ & $\begin{array}{c}\mathrm{DZ} \mathrm{I} \\
\text { (m) }\end{array}$ & $\begin{array}{r}\text { DZ II } \\
\text { (sec) }\end{array}$ \\
\hline \multirow{2}{*}{ IST1 } & $16.63 /$ & $2.93 /$ & $1.86 /$ & \multirow{2}{*}{1.14} & \multirow{2}{*}{35.55} & \multirow{2}{*}{3.72} & \multirow{2}{*}{5} & $66.15 /$ & \multirow{2}{*}{7.86} & 4.00 to \\
\hline & 3.1 & 1.35 & 1.1 & & & & & & & 5.76 \\
\hline \multirow{2}{*}{ ISW1 } & $15.55 /$ & $2.59 /$ & $1.7 /$ & \multirow{2}{*}{1.14} & \multirow{2}{*}{35.55} & \multirow{2}{*}{3.72} & \multirow{2}{*}{5} & $64.45 /$ & \multirow{2}{*}{12.69} & 2.86 to \\
\hline & 2.5 & 1.21 & 1 & & & & & 51.76 & & 5.34 \\
\hline \multirow{2}{*}{ IST2 } & $15.64 /$ & $2.98 /$ & $1.86 /$ & \multirow{2}{*}{1.14} & \multirow{2}{*}{34.67} & \multirow{2}{*}{3.72} & \multirow{2}{*}{5} & $58.86 /$ & \multirow{2}{*}{9.7} & 4.13 to \\
\hline & 2.7 & 1.27 & 1.1 & & & & & 49.16 & & 4.58 \\
\hline \multirow{2}{*}{ ISW2 } & $13.54 /$ & $2.53 /$ & $1.7 /$ & \multirow{2}{*}{1.14} & \multirow{2}{*}{34.67} & \multirow{2}{*}{3.72} & \multirow{2}{*}{5} & $51.60 /$ & \multirow{2}{*}{11.15} & 2.17 to \\
\hline & 3.7 & 1.43 & 1 & & & & & 40.45 & & 3.18 \\
\hline
\end{tabular}




\section{List of Figure Captions}

Fig 1. Snapshot of video data collected from study site 2

Fig 2. Estimation of startup loss time and saturation flow at signalized intersection

Fig 3. Red light violations at the start and end of red phase (a) percentage of cycles where red light violations occurred at the red phase (b) mean red light violations per red light violation cycle

Fig 4. Type of vehicles involved in red light violations per red light violation cycles during (a) first $10 \mathrm{sec}$ (b) last $10 \mathrm{sec}$ of red

Fig 5 (a). Observed frequency probability of stopped small car against time to stop line (TTS), (b) Observed typical type II dilemma zone for small cars during amber phase 


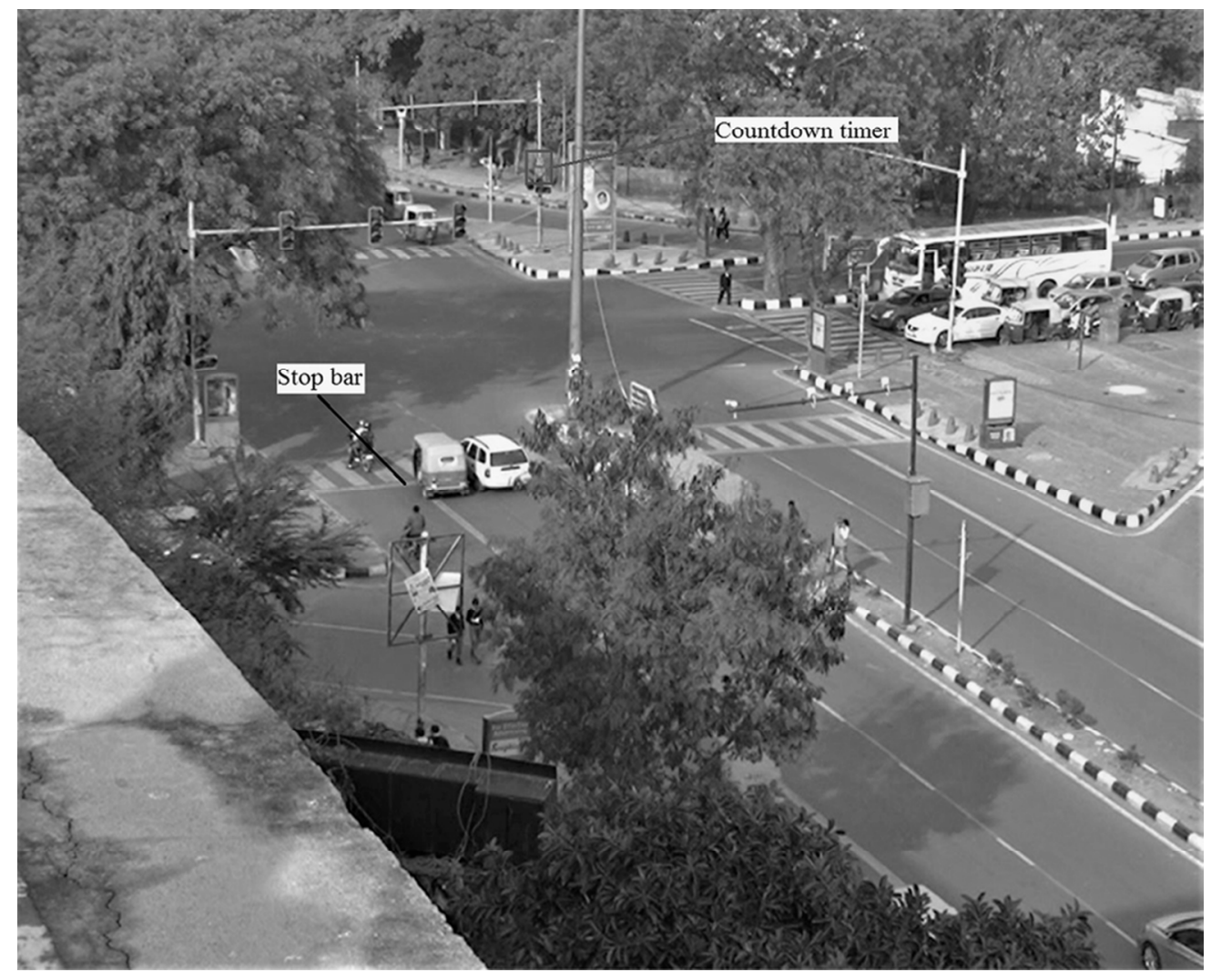

Snapshot of video data collected from study site 2

Fig 1

$80 \times 65 \mathrm{~mm}(300 \times 300 \mathrm{DPI})$ 


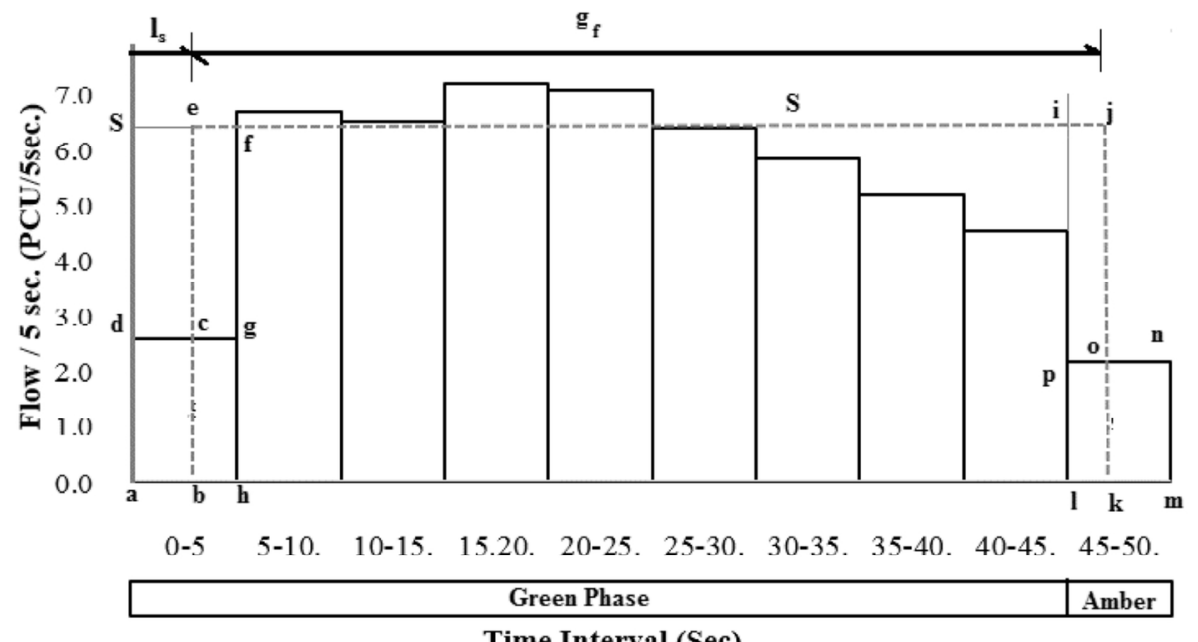

Fig 2. Estimation of startup loss time and saturation flow at signalized intersection Fig 2 $76 \times 39 \mathrm{~mm}(600 \times 600 \mathrm{DPI})$ 


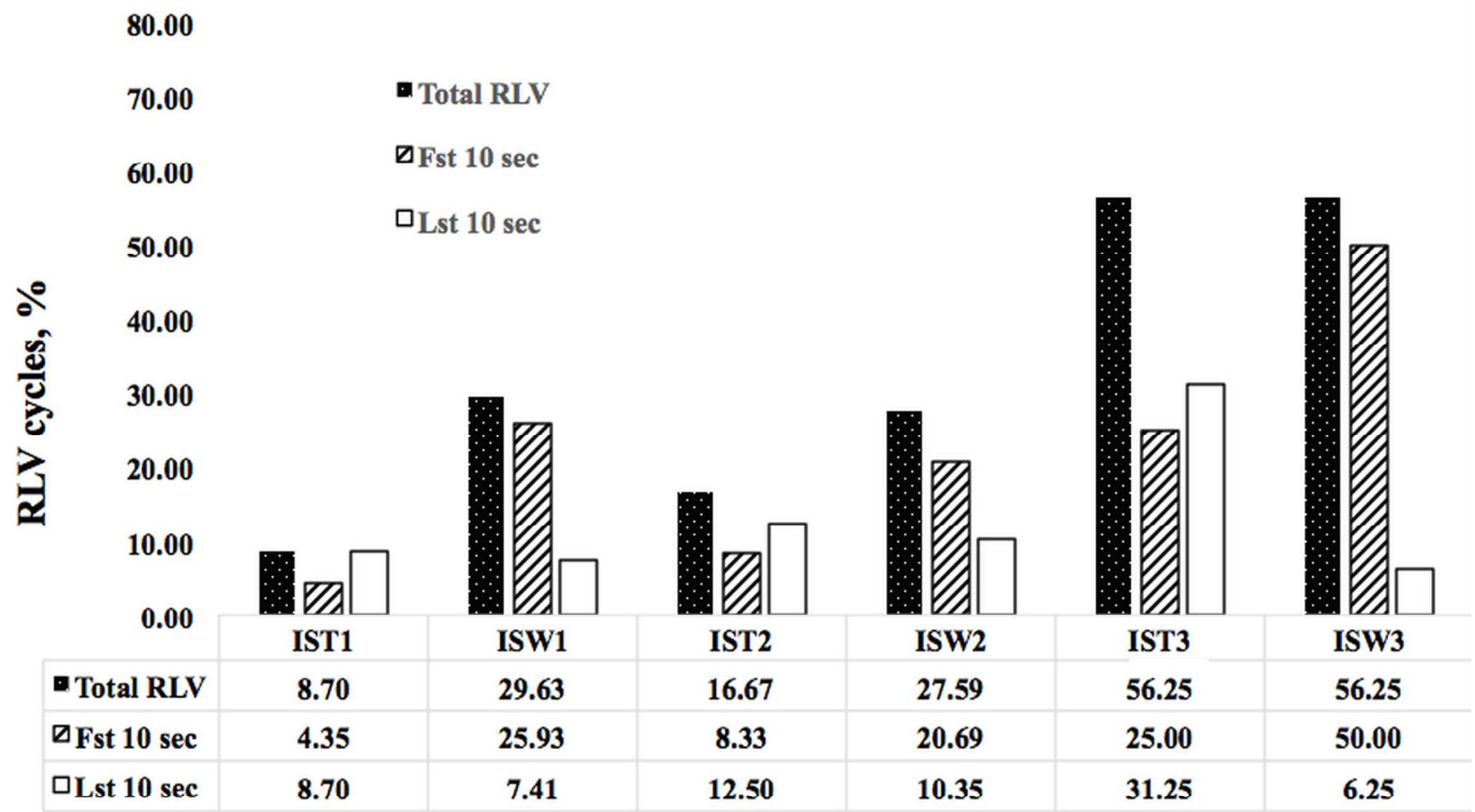

(a)

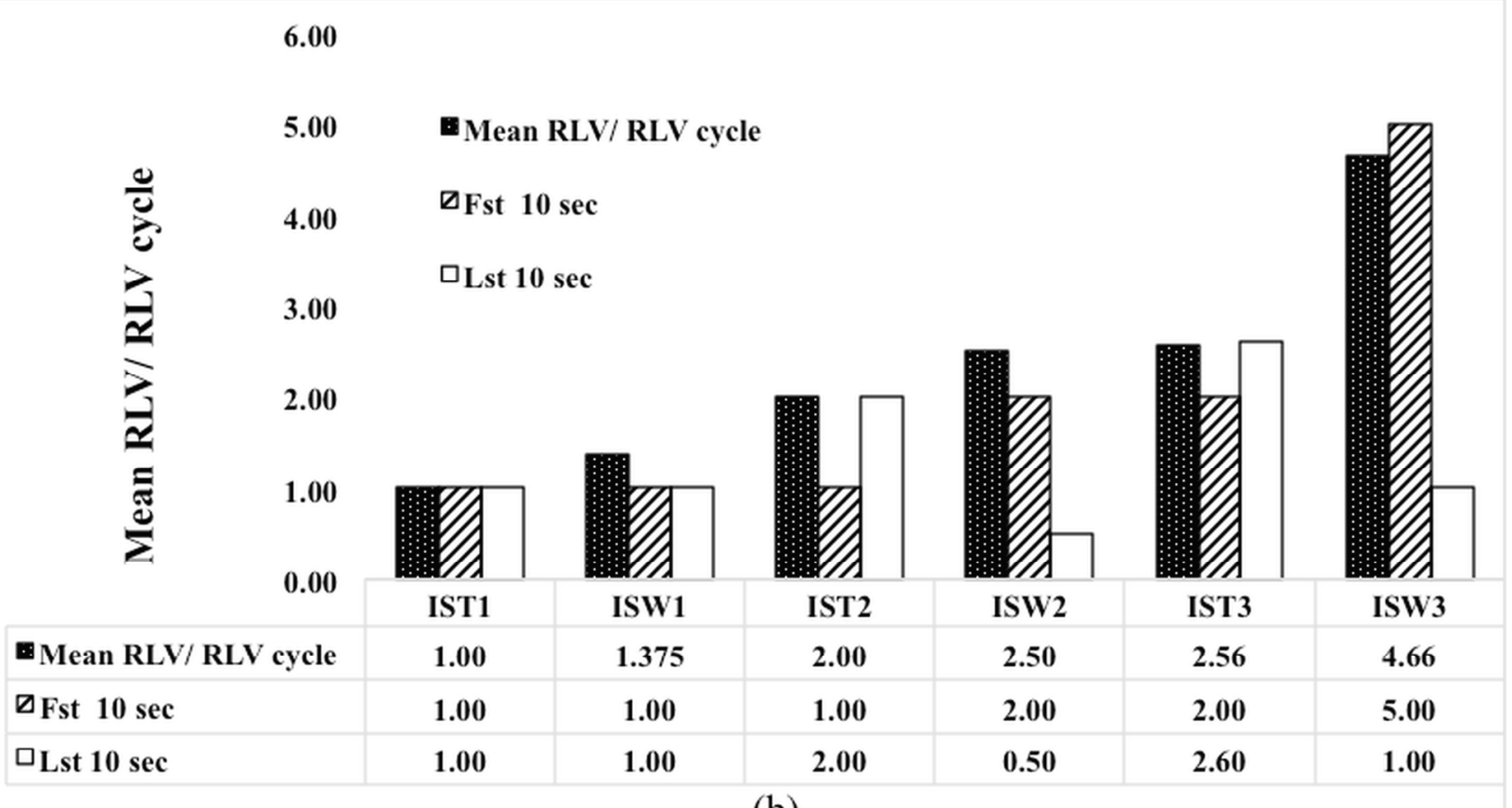

(b) 


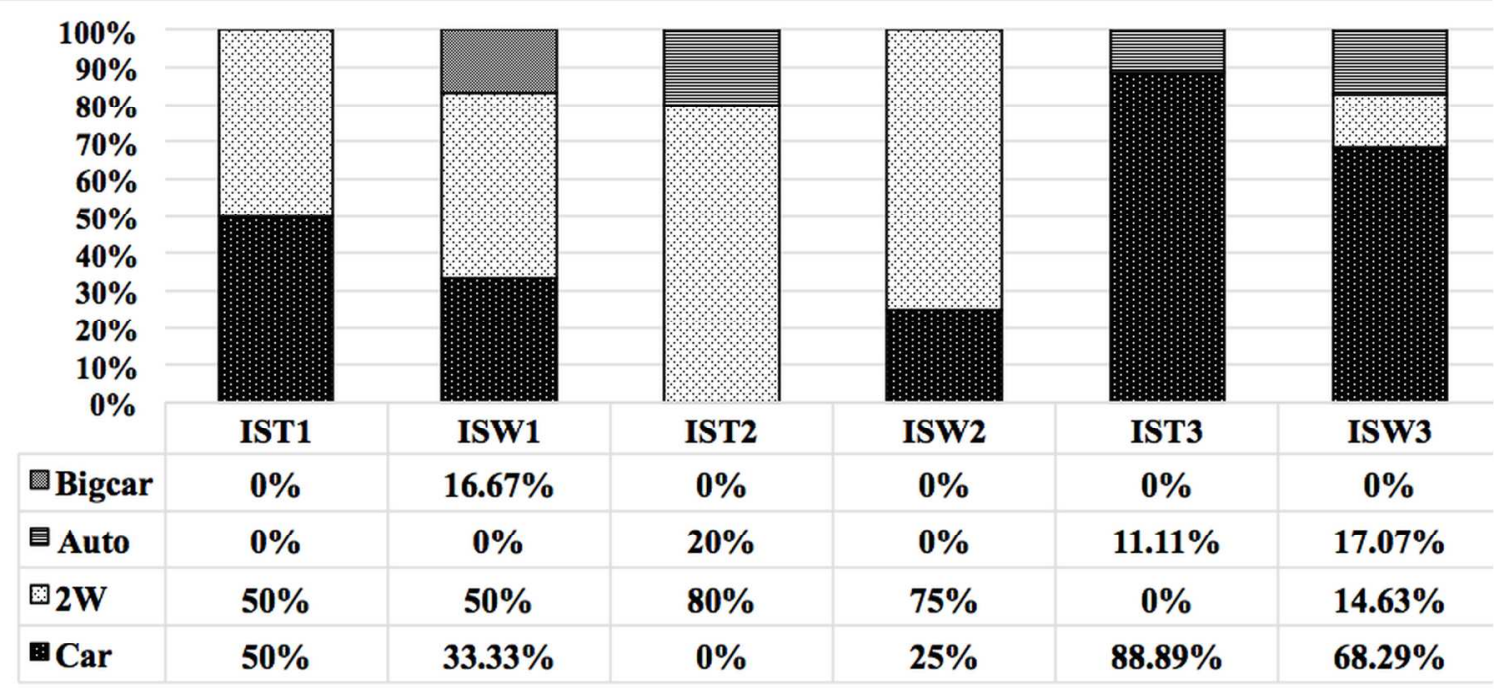

(a)

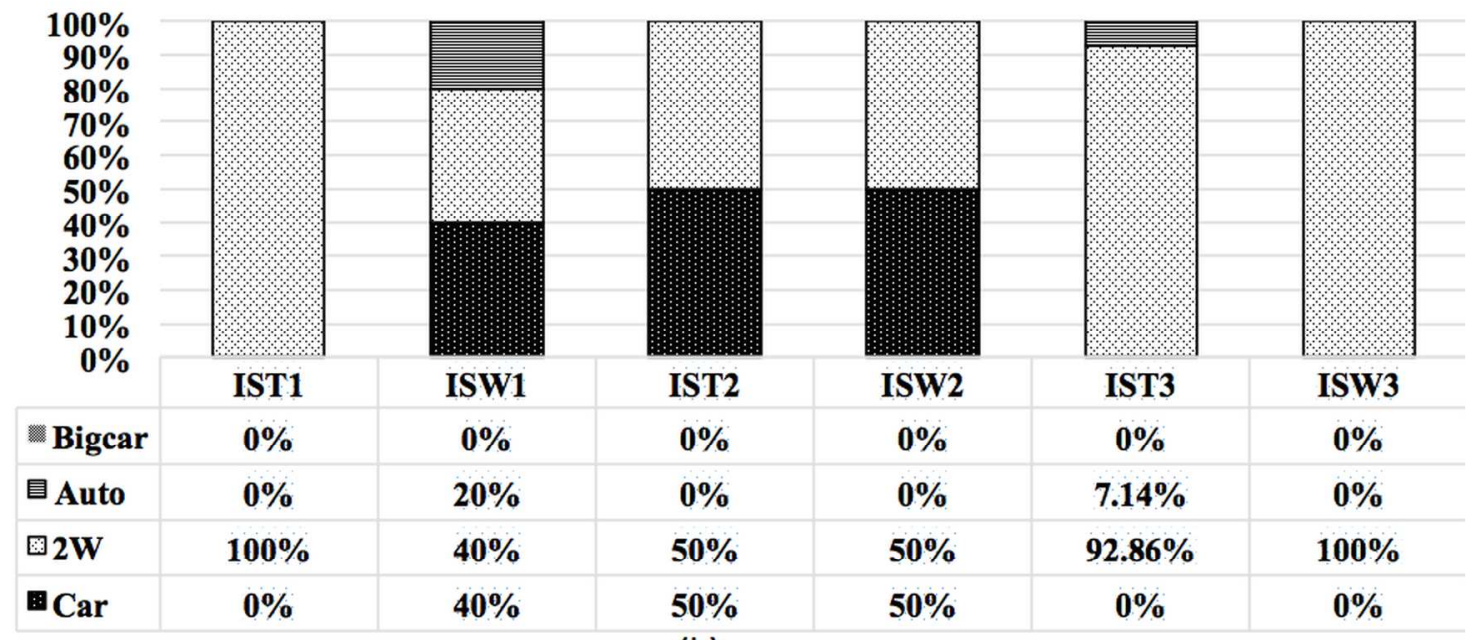

(b) 


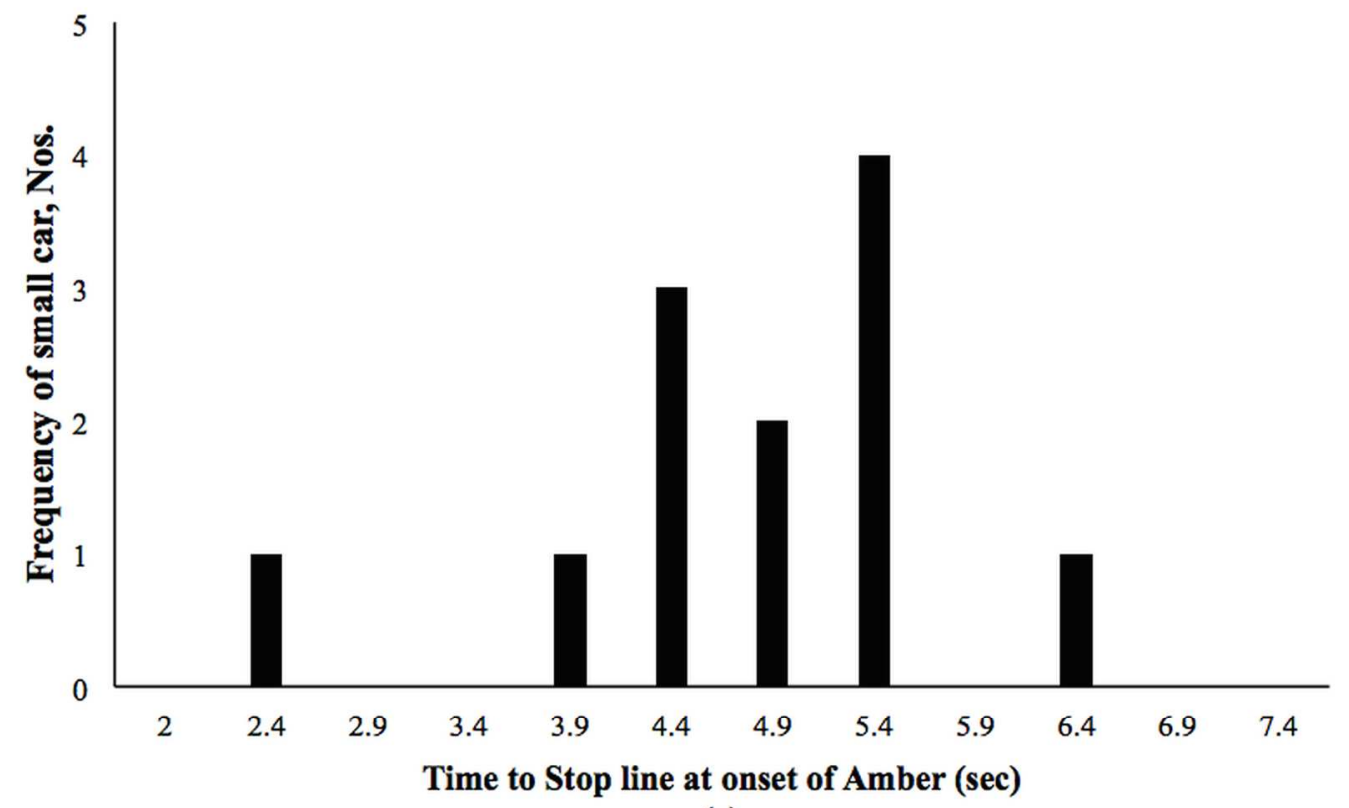

(a)

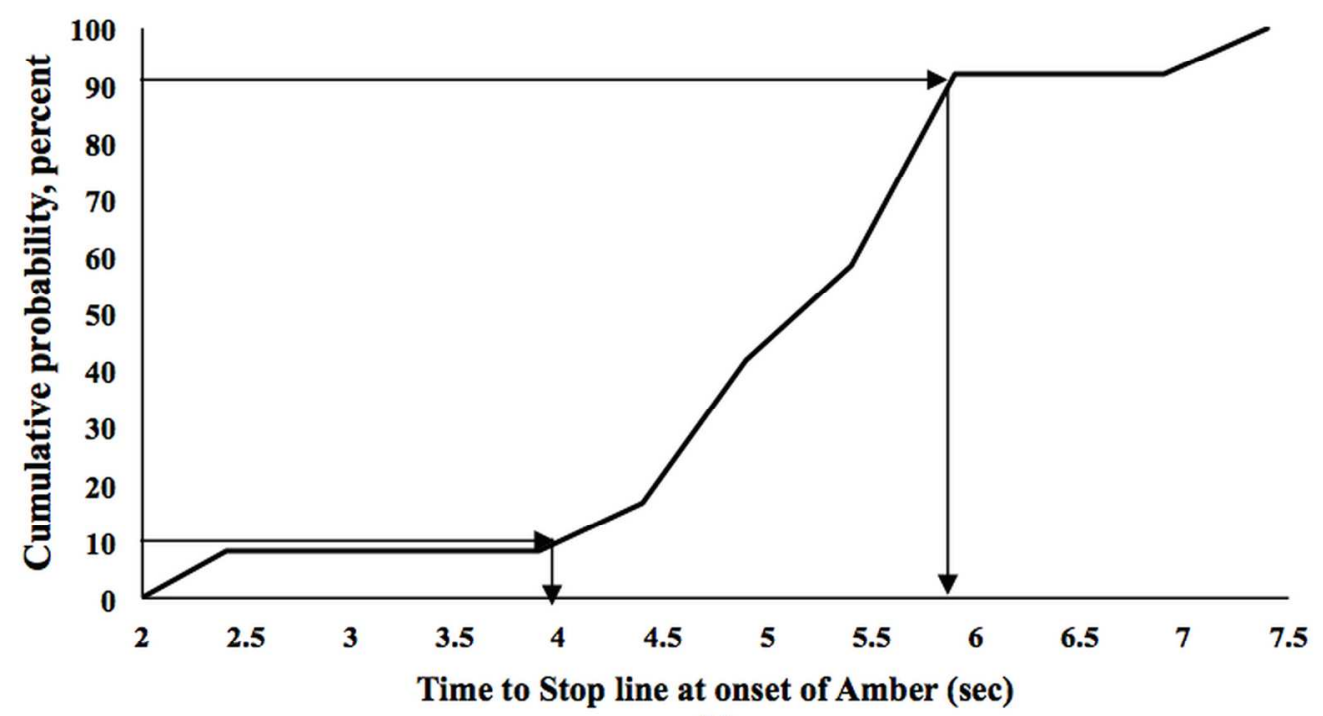

(b) 